\title{
Effects of visual imagery on the accommodation response
}

\author{
FREDERICK V. MALMSTROM \\ United States Air Force Academy, Colorado 80840 \\ and \\ ROBERT J. RANDLE \\ NASA/Ames Research Center, Moffett Field, California 94035
}

\begin{abstract}
Twenty-seven naive male subjects were tested to determine whether they could effect appropriate accommodation changes in an empty field by "thinking near" and "thinking far." Evidence indicated that naive subjects could effect significant and appropriate accommodation changes, but only about a steady-state value of 1.0 diopter. Additionally, the data support the hypothesis that the resting state of accommodation is not at the visual far point, but, rather, at about 1.0 diopter.
\end{abstract}

Questions arise as to whether concomitant accommodation changes occur in the eye when one is imagining near and far scenes. Hall $\cdot(1972)$ and Malmstrom (1972) had separately concluded that in certain cases of static visual imagery, eye movements in the appropriate direction accompanied the recall of visual percepts. As for accommodation changes, the data are less conclusive. Westheimer (1957), using an objective optometer, reported that two subjects, instructed to "think near" and "think far" while viewing an empty field, were able to effect accommodation changes of only 0.5 diopters (D), and that these changes were only transitory. However, this brief statement did not specify the duration of the change, the starting point of focus, or the direction of the change in accommodation. Malmstrom and Randle (Note 1) had determined that imagery aids in accommodating in the appropriate direction; it was found that the gross empty field accommodation response occurs at the rate of $4.0 \mathrm{D}$ per minute, a slow response, indeed. However, this finding must be taken with caution. The responses were taken to only $30 \mathrm{sec}$ of duration, and it was not at all clear whether the eye was tending toward an involuntary resting state of accommodation or whether the subjects had exhibited true volitional control over accommodation. Additionally, it was determined

F. V. Malmstrom's present address is: Department of Psychology, Oklahoma State University, Stillwater, Oklahoma 74074. This research was funded, in part, by the U.S. Air Force Systems Command Research Contract HMD/RDOP 74-4; however, the opinions expressed herein do not necessarily reflect those of the Air Force Systems Command or of the United States Air Force. The authors would like to express their appreciation for the assistance of Ms. Donna $L$. Miller in the reduction of data and the operation of the Cornsweet and Crane optometer. Requests for reprints should be sent to the second author. that these naive subjects were unable to override accommodation on a point-source target stimulus by "thinking near" or "thinking far" once they had been able to establish clear focus on this target stimulus for at least $30 \mathrm{sec}$. Randle (Note 2) has shown that trained subjects can exhibit volitional control over accommodation in both empty and fixed-focus fields. More recently, Provine and Enoch (1975) have demonstrated that subjects could learn to exhibit as much as $9.0 \mathrm{D}$ volitional control of accommodation while wearing a soft contact lens. Indeed, some trained subjects have been shown to exercise volitional control over accommodation almost as well as if they had been viewing an actual visual scene.

Over the past two decades, it has been well established that when the untrained eye looks into either a dark or an empty luminous field, it exhibits a phenomenon known as empty-field myopia (Morgan, 1957). Thus, for example, if a pilot were searching for a distant target in either darkness or fog, his eye would, instead, pick a point about $1 \mathrm{~m}$ in front of his eye. His point of focus would then tend to wander only slightly about this value. Targets which are very faint may never be detected unless the distance of accommodation matches the distance of the target. Furthermore, it has been suggested in some preliminary work by the authors that accommodation may be influenced by factors other than mere focus information. Clark, Randle, and Stewart (1975) reported a severe vestibularrelated myopia in subjects tested in both stimulus and empty-field conditions. For subjects tested in emptyfield conditions, effects as great as $1.5 \mathrm{D}$ myopia were noted, and effects appeared significant for as long as $100 \mathrm{sec}$ after abrupt deceleration. Malmstrom, Randle, and Weber (Note 3) reported that accom- 
modation could be degraded by the addition of concurrent mental tasks. Westheimer (1957) went so far as to intentionally insult his two subjects and noted a rise in accommodation values of up to $1.0 \mathrm{D}$ for periods as long as $5 \mathrm{~min}$. Preliminary observations as this lend some support to the anecdote that a person is "so upset he can't see straight." Clearly, this loss of visual acuity may not be a desirable side effect.

Finally, Morgan (1957), Schober (1954), and, more recently, Hennessy et al. (1975) and Leibowitz and Owens (1975) have seriously questioned the assumption, as many textbooks imply, that the resting state of accommodation is at infinity. If the resting state of accommodation is some point other than infinity, it may be that all changes in accommodation vary about this resting point. To focus on a target at infinity would, therefore, require negative accommodation. This process would suggest that the sympathetic system be innervated to override some equilibrium position hypothesized to constitute a resting state of accommodation.

\section{Empty-Field (Open-Loop) Imagery}

The purpose of this experiment was to determine whether naive subjects could override perceptual accommodation by "thinking near" and "thinking far." It was decided to determine whether naive subjects could effect volitional accommodation changes in an empty visual field, given a known initial accommodative state. Because many subjects consider visual imagery tasks rather fatiguing (Weber \& Castleman, 1970), it was decided to limit the experimental portions of this experiment to a l-min duration. The findings of Malmstrom and Randle (Note 1) had indicated that accommodation changes in empty fields were too slow to be studied meaningfully in shorter trials. Therefore, the observation period needed to be extended to at least $1 \mathrm{~min}$.

\section{METHOD}

\begin{abstract}
Subjects
The subjects were 2717 - to 25 -year-old males with at least a high school education. The requirement for age was to insure that all subjects had a wide range of accommodation. Although prior screening with a Bausch and Lomb orthorater indicated that all subjects had $20 / 20$ vision, the experimental equipment revealed that about half of the subjects were up to $1.0 \mathrm{D}$ myopic, and the other half were up to $1.0 \mathrm{D}$ hyperopic. Results from 5 additional subjects were not used either because of a small pupillary diameter, rendering accommodation measurements unusable, or because of an inability to follow instructions. All data were taken from the left eye; the right eye was occluded. All subjects were paid $\$ 7$ for participating in an experimental session that lasted about $2 \mathrm{~h}$.
\end{abstract}

\section{Stimuli and Apparatus}

All measurements were taken with the Cornsweet and Crane (1970) objective optometer. All subjects were presented a black " $x$ " target subtending a visual angle of about $3 \mathrm{deg}$, focused at $0,1,2$, or $3 \mathrm{D}$. A $0.3-\mathrm{mm}$-diam selsyn-actuated aperture was dropped into place at a plane in the optical system such that it was imaged in the plane of the entrance pupil of the subject's eye. At the same instant, the " $x$ " target background brightness was increased to maintain a constant brightness under the two viewing conditions. The eye's entrance pupil was now $0.3 \mathrm{~mm}$, a condition which increased the depth of field to an extent that the target was always in clear focus. Retinal blur and blur changes were now absent, and accommodation was not required. This was called the "open-loop" mode and is analogous to empty-field viewing, in that accommodation is independent of the object field. Nonvisual factors affecting accommodation are now dominant to the extent to which they can, indeed, influence accommodation.

After an initial calibration procedure, the subject's left eye was tested to determine the near and far point to the closest $0.1 \mathrm{D}$. The points were determined using the Crane and Cornsweet (1970) focus stimulator as a subjective Badal optometer.

\section{Instructions and Procedures}

All subjects were informed that this was an experiment concerning visual imagery and its effects on involuntary eye processes. At no time during the experiment was the subject informed as to the apparent depth of the target, but only that he was to hold the target in focus until further instructions were given. With the focus stimulator, all targets maintain the same relative brightness and angular size, so these factors cannot be used as distance cues. Each subject focused on a $0,1,2$, or $3 \mathrm{D}$ " $x$ " target for $15 \mathrm{sec}$. If the subject was $1.0 \mathrm{D}$ myopic, he was presented targets of $1,2,3$, and $4 \mathrm{D}$, and so forth, depending on each subject's refractive error, if any. In short, the subject's lowest diopter setting was his previously measured far point.

At the end of the 15-sec stabilization period, the " $x$ " target was switched to the open-loop mode for $60 \mathrm{sec}$. Simultaneously, the "think-near" group was instructed to imagine the open-loop target "as near as possible"; the "think-far" group was instructed to imagine the open-loop target "as far away as possible"; and the "watch-the-target" group was instructed merely to "watch the target" under the open-loop conditions. Data from the optometer were recorded continuously on a Brush recorder and sampled at 5 -sec intervals. This sampling resulted in 13 instantaneous measures.

\section{RESULTS}

Analysis of variance for the entire 60 -sec period shows significant main effects for the original starting conditions of the target from the eye of $0,1,2$, and $3 \mathrm{D}, F(3,72)=51.82, p<.001$, and for the rate of change of accommodation, Time Blocks 1 through $13, F(12,288)=17.80, p<.001$. There is also a twoway interaction between the time blocks and the starting conditions, $F(36,288)=32.27, p<.001$.

Analysis of variance for Time Blocks 7 through 13 (30 through $60 \mathrm{sec}$ ) shows significant main effects for the "think-near," "think-far," and "watch-thetarget" conditions, $F(2,24)=117.73, p<.001$, and the original starting conditions of $0,1,2$, and $3 \mathrm{D}$, $F(3,144)=119.48, \mathrm{p}<.001$. There is also a two-way interaction of the "think-near, "think-far," and "watch-the-target" $\times$ starting conditions of $F(6,72)=3.76, p<.001$. No other main or interaction effects were noted. Mean values for the "think-near," "think-far," and "watch-the-target" cells, plotted as a function of the starting conditions and time blocks are shown, respectively, in Figure 1. 

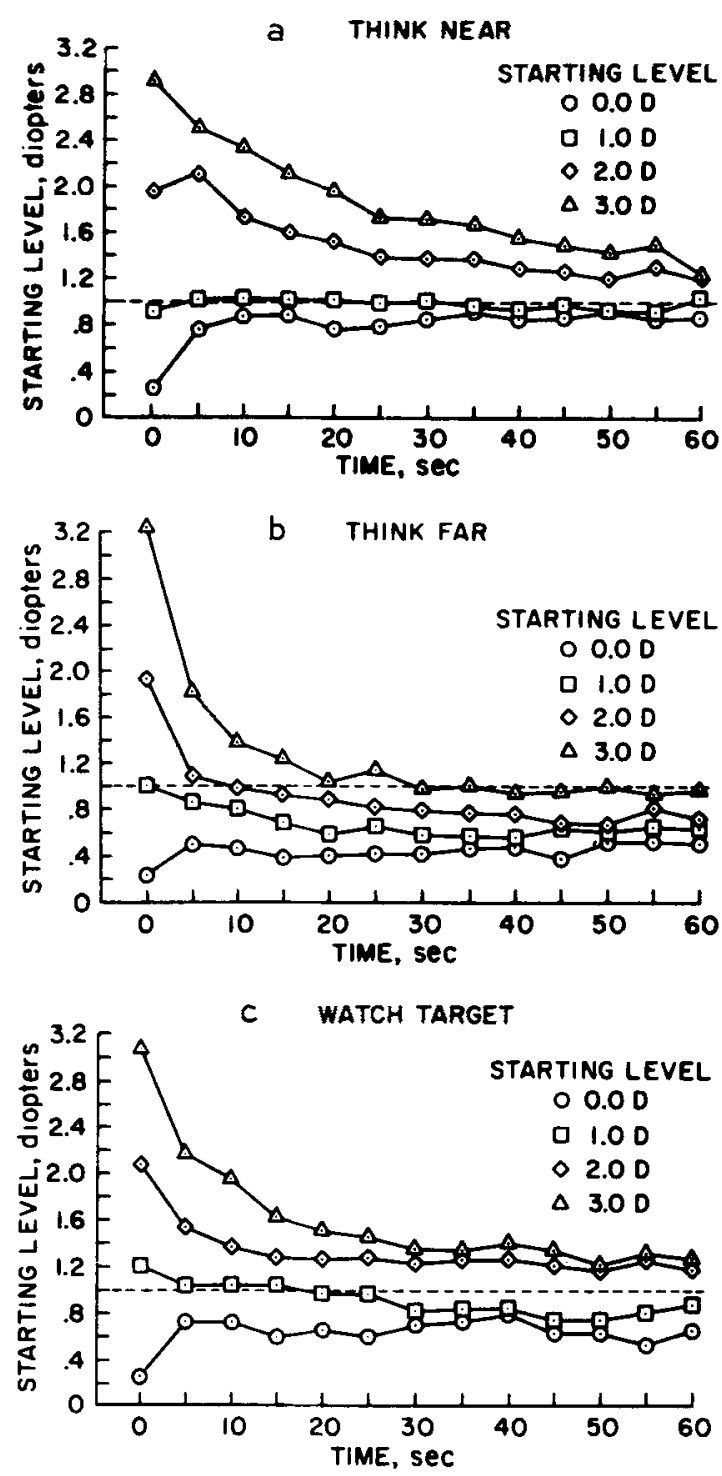

Figure 1. (a) Mean accommodation level in the open-loop mode as a function of time, starting level, and instructions to "think near"'; $\mathbf{N}=9$. (b) Mean accommodation level in the open-loop mode as a function of time, starting level, and instructions to "think far"; $N=9$. (c) Mean accommodation level in the open-loop mode as a function of time, starting level, and instructions to "watch target"; $\mathbf{N}=9$.

\section{DISCUSSION}

Results are divided into two separate analyses of variance, time blocks of 1 through 13 (0 through $60 \mathrm{sec}$ ) and time blocks of 7 through 13 (30 through $60 \mathrm{sec}):$

$0-60$ seconds. Overall, it would appear that, regardless of the instruction to "think near," "think far," or "watch the target," accommodation tends toward an equilibrium value of about $1.0 \mathrm{D}$. The entire empty-field accommodation is a very slow function of time, and the empty field value of accommodation which the eye eventually settles upon is very dependent upon the distance at which the eye was last focused. That is, if the eye was watching a target at, say, $2.0 \mathrm{D}$ and the target was removed, the eye would tend to "stick" at $2.0 \mathrm{D}$. Randle (1975) has described this effect as a kind of biological hysteresis. In the past, empty-field myopia experiments have not generally specified the distance the eye was originally focused upon. Hence, it might be useful if the eye were kept in empty-field conditions at least a minute or two before taking any measurements.

30-60 seconds. It would be useful to determine the effects of visual imagery after empty-field myopia appears complete. Therefore, by inspection, the time period of 30 to $60 \mathrm{sec}$ was taken to be such a condition. Significant results are, indeed, obtained for the "think-near," "think-far," "watch-the-target" conditions from 30 to $60 \mathrm{sec}$, indicating that visual imagery is useful in altering the accommodative system in the appropriate direction. However, even after $30 \mathrm{sec}$ of viewing in the open-loop conditions, the residual effects of the starting conditions of 0,1 , 2 , and $3 \mathrm{D}$ are still very much evident, shown by the main effect and by the interaction effect of "thinknear," "think-far," "watch-the-target" $\times$ starting conditions.

Figure 2 shows the results of the experiment collapsed over both trials and starting conditions of $0,1,2$, and $3 \mathrm{D}$.

Particular attention should be drawn to the period from 30 to $60 \mathrm{sec}$. Mean differences in the accommodative states of "think near" and "think far" vary from 0.35 to $0.55 \mathrm{D}$. Although these differences are small compared to "meaningful" accommodation on stimulus objects, they are, nevertheless, statistically significant under steady-state open-loop conditions. Evidence would suggest that all subjects have some rudimentary cortical control or, at least, mediation of accommodation. Additionally, inspection of individual differences would indicate that



Figure 2. Open-loop mean accommodation level of each of the three groups with differing instructions as a function of time and collapsed over starting levels. 
some subjects were more successful with the "thinknear," "think-far" instructions only during the first $30 \mathrm{sec}$ of the experimental conditions. Once they had arrived at the steady-state condition of around $1.0 \mathrm{D}$, these subjects were no more successful at effecting changes in accommodation than any other subjects.

\section{CONCLUSION}

There appear to be at least two separate visual accommodation effects at work in empty-field conditions. The first is identified as the classic empty-field myopia, which slowly drifts toward an eventual resting value of around 1.0 D. Empty-field myopia may take as long as 1 or $2 \mathrm{~min}$ to fully develop, depending upon the distance at which the eye was last focused. The second effect is due to a much weaker visual imagery process. Under empty-field (open-loop) conditions, "thinking near" and "thinking far" can accelerate or retard the inevitable drift toward empty-field myopia, as shown in Figure 1. Once the accommodative system has stabilized near 1.0 D, visual imagery responses persist as residuals, as shown in Figure 2. It has been shown, however, that trained subjects can exhibit volitional control over visual accommodation using appropriate feedback techniques, essentially ignoring the stimulus field (Provine \& Enoch, 1975; Randle, Note 2) and taking full advantage of the incipient control shown here.

In the past, there has been considerable confusion as to whether visual imagery is useful in learning the appropriate accommodative response (Cornsweet \& Crane, 1973; Provine \& Enoch, 1975; Westheimer, 1957; Malmstrom \& Randle, Note 1). This confusion may, in the future, be resolved if the two accommodative effects are accounted for separately.

\section{REFERENCES NOTES}

1. Malmstrom. F. V., \& Randle. R. J. Visual imagery in the third dimension. Paper published in Proceedings of Psychology in the Air Force Symposium. 25-27 April 1974. Department of Life and Behavioral Sciences. USAF Academy. Colorado 80840.
2. Randle, R. J. Volitional control of visual accomodation. Conference Proceeding No. 82 on Adaptation and Acclimatization in Aerospace Medicine. AGARD, NATO, 14-18 September 1970. Garrisch-Partenkirchen, Germany.

3. Malmstrom, F. V.. Randle, R. J.. \& Weber, R. J. Perceptual tumnel or perceptual sphere? Accomodation and stress. Paper presented to Rocky Mountain Psychological Association. 7-10 May 1975, Salt Lake City, Utah

\section{REFERENCES}

Clark, B., Randle, R. J., \& Stewart, J. D. A vestibularocular accommodation reflex in man. Aviation. Space, and Environmental Medicine. 1975, 46, 1336-1339.

Cornsweet, T. N.. \& Crane. H. D. Servo-controlled infrared optometer. Journal of the Optical Society of America, 1970. 60. 548 .

Cornsweet. T. N., \& Crane, H. D. Training the visual accommodative system. Vision Research. 1973. 13. 713-715.

Crane, H. D.. \& Cornsweet, T. N. Ocular-focus stimulator. Journal of the Optical Society of America, 1970, 60, 577.

HALL. D. C. The effect of eye movements on the recall of information with visual imagery. Unpublished dissertation. Stanford University, 1972.

Hennessy, R. T.. IIDa, T., ShiIna, K., \& Leibowitz, H. W. The effect of pupil size on accommodation. Vision Research, 1975. in press.

Leibowitz. H. W., \& Owens, D. A. Night myopia and the intermediate dark focus of accommodation. Journal of the Optical Society of America, 1975. 65. 1121.

Malmstrom, F. V. Visual fixations about an imaginary letter matrix. Unpublished thesis. Oklahoma State University. 1972.

Morgan. M. W.. JR. The resting state of accommodation. American Joumal of Optometry and Archives of American acudemy of Optometry. 1957, 7, 347-352.

Provine, R. R.. \& Enoch. J. M. On voluntary ocular accommodation. Perception \& Psychophysics, 1975. 17, 209-212.

RANDLE. R. J. The non-visual in visual accommodation. In Proceedings, IEEE International Conference on Cybernetics and Society. San Francisco, 23-25 September 1975.

SCHOBER, H. Über die Akkommodationsruhelage (On the resting position of accommodation). Optik, 1954, 11. 282-290. (Trans. R. Kaeck \& H. Leibowitz, Department of Psychology, Pennsylvania State University. University Park. Pennsylvania 16802. October 1968.)

Weber. R. J.. \& Castleman. J. The time it takes to imagine. Perception \& Psychophysics. 1970. 8, 165-168.

Westhermer. G. Accommodation measurements in empty ficlds. Journal of the Optical Society of America, 1957, 47. 714-718.
(Received for publication June 1975; revision received January 1976. .) 